\title{
EFFICACY OF COMBINATION OF ASPIRIN WITH PHOSPHODIESTERASE TYPE 5 INHIBITORS IN PHOSPHODIESTERASE TYPE 5 INHIBITORS NON- RESPONDERS ERECTILE DYSFUNCTION PATIENTS
}

By

\section{Ahmed Abd El-Monem Ali Al-Ashkar, Abd El-Raouf Mohamed Al- Mohsen and Mohamed Ismail M. Kamel}

Department of Dermatology, Venereology and Andrology, Faculty of Medicine, Al-Azhar University

Corresponding Author: Ahmed Abd El-Monem Ali Al-Ashkar,

Phone: +201146950580, E-mail: ahmed.m2095@gmail.com

\begin{abstract}
Background: Erectile dysfunction (ED) is a worldwide health problem causing significant impact on the quality of life of men and their partners. The etiology of ED may be organic, psychogenic or mixed. There were many treatment options for ED, but oral phosphodiesterase type 5 inhibitors are considered the first line of treatment with considerable therapeutic failure rate. Phosphodiesterase type 5 inhibitors therapeutic failure is considered a treatment challenge. Many modalities to overcome phosphodiesterase inhibitors failure or no response had been developed.
\end{abstract}

Objective: To evaluate the efficacy of aspirin when combined with phosphodiesterase inhibitors in erectile dysfunction phosphodiesterase non-responders patients.

Patients and methods: The current study was carried out on 40 patients with ED that did not respond to on demand phosphodiesterase inhibitors. Patients were recruited from outpatient clinic of Dermatology, Venerology and Andrology Department, Faculty of Medicine, Al-Azhar University Hospitals from December 2019 to October 2020. A regimen of sildenafil on demand and tadalafil daily for 6 weeks to overcome the phosphodiesterase inhibitors type 5 non response. All the studied patients received $100 \mathrm{mg}$ aspirin daily combined with sildenafil and tadalafil for another 6 weeks to evaluate the effect of adding aspirin on the ED status of the patients. The patients were evaluated using a 5-items version of the International Index of Erectile Function (IIEF-5).

Results: The results revealed non-significant improvement after added aspirin to sildenafil and tadalafil in comparison to the same studied group taking sildenafil and tadalafil only. The evaluation was done using a 5items version of the International Index of Erectile Function (IIEF-5).

Conclusion: aspirin combination with PDE5i added no more efficacy than PDE5i alone in ED PDE5i nonresponders patients.

Keywords: Erectile dysfunction, Phosphodiesterase 5 inhibitors, Aspirin $100 \mathrm{mg}$. 


\section{INTRODUCTION}

Erectile dysfunction (ED) defined as a persistent inability to achieve or maintain an erection sufficient for sexual satisfaction (Allen and Walter, 2019). It is an age dependent disease, about $40 \%$ of men aged 40 years, and $70 \%$ of men aged 70 years have some degree of ED (Retzler, 2019). ED etiology may be vasculogenic, neurogenic, endocrinal, drug induced and psychogenic (Yafi et al., 2016). Oral phosphodiesterase type 5 inhibitors (PDE5i) (sildenafil, tadalafil, vardenafil and avanafil) are the first line treatment of ED. PDE5i do not induce spontaneous erection but erection occurs only when coupled with sexual stimulation (visual, cerebral, or physical). PDE5i hydrolyzes cyclic guanylate monophosphate (cGMP) specifically to $5^{\prime}$ GMP that cause penile cavernous smooth muscle relaxation and penile erection (Bayraktar and Albayrak, 2019). In general, about 30-35\% of patients fail to respond (Non-responders) to PDE5i (Lee and Sharifi, 2018). Aspirin is a prototype of non-steroidal antiinflammatory drugs (NSAIDs) and it has analgesic, antipyretic, anti-inflammatory, and anti-platelet aggregation effect (Fuster and Sweeny, 2011). Aspirin has an inhibitory effect on platelet activation process, suggesting that a prostaglandin (PG) is involved in the activation process. However, Aspirin induces its antiplatelet aggregation effect by reducing thromboxane A2 (TXA2) synthesis, which is a strong platelets aggregator, vasoconstrictor agent and essential for aging process. Aspirin reduces TXA2 synthesis by irreversibly inhibiting COX-1 enzyme activity. Ultimately, the antithrombotic effect of aspirin occurs as the inhibition of Thromboxane A2 synthesis (Bayraktar and Albayrak, 2018). Considering the protective role of aspirin against cardiovascular diseases (CVD) and cerebrovascular diseases, aspirin may enhance erectile function through its antiinflammatory effect as there is low-grade inflammatory processes or high circulating pro inflammatory markers also related to the ED process through its effect on endothelium (Li et al 2018).

The aim of this study was to evaluate the efficacy of aspirin 100mg in combination with PDE5i (sildenafil $100 \mathrm{mg}$ and tadalafil $5 \mathrm{mg}$ ) in treatment of ED non-responders patients.

\section{PATIENTS AND METHODS}

This study was carried out on 40 patients with ED that did not respond to regular phosphodiesterase inhibitors on demand (non-responders) from December 2019 to October 2020. The patients were diagnosed by history and intracavernosal injection (ICI). The patients were able to read and give consents. Patients under 18 years old, with present or past history of bleeding disorders and with severe end organ damage, were excluded. Patients were selected from outpatient clinic of Dermatology, Venereology and Andrology Department of Faculty of Medicine Al-Azhar University Hospitals. All patients were subjected to complete history (medical, sexual), examination (general, genital) and ICI assessment.

All studied patients were on baseline on demand treatment with sildenafil 100 $\mathrm{mg}$ before enrollment in the current study. Yet all were non-responders. After enrollment in the study, all patients, beside the baseline sildenafil, were treatment with tadalafil $5 \mathrm{mg}$ daily dose 
for 6 weeks. Aspirin $100 \mathrm{mg}$ daily was added to the previous regimen for additional 6 weeks. The studied patients were evaluated using a 5-items version of the International Index of Erectile Function (IIEF-5) before treatment with the combination of sildenafil and tadalafil and after 6 weeks of this regimen and after adding aspirin.

All patients answered the validated Arabic version of IIEF-5 questionnaire (Shamloul et al., 2004)

Statistical analysis: Data were analyzed using statistical pachage for the social sciences (SPSS) version 24. Quantitative data were expressed as mean \pm standard deviation (SD) and range. Qualitative data were expressed as frequency and percentage.

Mann-Whitney $\mathbf{U}$ test was used when comparing between two means (for abnormal distributed data).

IQR: It is the measure of statistical dispersion, being equal to the difference between $75^{\text {th }}$ and $25^{\text {th }}$ percentile.

\section{RESULTS}

The current study was conducted on 40 ED non-responders patient to on demand PDE5 inhibitors. The mean age of all studied patients was $60.7 \pm 6.7$ years with minimum age of 49 years and maximum age of 73 years and the mean duration of ED of all studied patients was $6.2 \pm 2.07$ years with minimum duration of 4 years and maximum duration of 12 years. All patients in the study were evaluated for medical diseases and revealed that $50 \%$ of patients $(n=20)$ had DM, $15 \%$ of patients $(n=6)$ had hypertension, $12.5 \%$ of patients $(\mathrm{n}=5)$ had benign prostatic hyperplasia, $5 \%$ of patient $(n=2)$ had hypercholesterolemia and $30 \%$ of patients had no history of medical diseases. All studied patients were evaluated with intracavernosal injection (ICI) using alprostadil and there were $35 \%$ of patients $(\mathrm{n}=14) \mathrm{E} 1,15 \%$ of patients $(\mathrm{n}=6) \mathrm{E} 2$, $37.5 \%$ of patients $(n=15)$ E3 and $12.5 \%$ of patients $(\mathrm{n}=5)$ E4 (Table 1).

Table (1): Description of demographic data of all studied patients

\begin{tabular}{|c|c|c|c|}
\hline \multicolumn{2}{|c|}{$\begin{array}{r}\text { Studied patients } \\
\text { (N = 40) }\end{array}$} & \multicolumn{2}{|c|}{} \\
\hline \multirow{2}{*}{ Parameters } & Mean \pm SD & \multicolumn{2}{|c|}{$60.7 \pm 6.7$} \\
\hline \multirow{2}{*}{ Age(years) } & Min - Max & \multicolumn{2}{|c|}{$49-73$} \\
\cline { 2 - 4 } Duration(years) & Mean \pm SD & \multicolumn{2}{|c|}{$6.2 \pm 2.07$} \\
\cline { 2 - 4 } & Min - Max & \multicolumn{2}{|c|}{$4-12$} \\
\hline \multirow{3}{*}{ Medical diseases } & Non & 12 & $30 \%$ \\
\cline { 2 - 4 } & DM & 20 & $50 \%$ \\
\cline { 2 - 4 } & HTN & 6 & $15 \%$ \\
\cline { 2 - 4 } & BPH / LUTS & 5 & $12.5 \%$ \\
\hline & Cholesterol & 2 & $5 \%$ \\
\hline
\end{tabular}


The current study showed a significant improvement in IIEF-5 score when daily tadalafil $5 \mathrm{mg}$ was added to on demand sildenafil $100 \mathrm{mg}$ and showed no significant improvement when daily aspirin was added to sildenafil and tadalafil (Table 2).

Table (2): Comparison between IIEF-5 score (baseline \& after 100mg sildenafil on demand and 5mg tadalafil daily $\&$ after adding aspirin)

\begin{tabular}{|c|c|c|c|c|}
\hline Score & $\begin{array}{c}\text { On demand } \\
\text { sildenafil } \\
(\mathbf{N}=\mathbf{4 0})\end{array}$ & $\begin{array}{c}\text { After 100mg } \\
\text { sildenafil on } \\
\text { demand and } \\
\text { IIEF-5 tadalafil } \\
(\mathbf{N}=\mathbf{4 0})\end{array}$ & $\begin{array}{c}\text { After adding } \\
\text { aspirin } \\
\mathbf{( N = 4 0 )}\end{array}$ & P-value \\
\hline Median & 8.5 & 15 & 16 & $<0.001$ \\
\hline IQR & $1-3$ & $10-17$ & $10.5-18$ & $>0.05$ \\
\hline
\end{tabular}

\section{DISCUSSION}

This study was carried out on 40 patients complaining of ED and not responding to ordinary PDE5i on demand dosing regimen. All patients in the study were treated with sildenafil $100 \mathrm{mg}$ on demand and tadalafil $5 \mathrm{mg}$ daily for 6 weeks followed by adding aspirin to the previous regimen for similar duration.

Bayraktar and Albayrak (2019) evaluated the efficacy and safety of adding aspirin $100 \mathrm{mg}$ to tadalafil $5 \mathrm{mg}$ versus tadalafil $5 \mathrm{mg}$ or aspirin $100 \mathrm{mg}$ alone in erectile dysfunction. They found that IIEF-EF scores increased in the aspirin, tadalafil, and combination groups but the combination of tadalafil and aspirin showed the best results. These findings suggested that aspirin and tadalafil were effective treatment options in the treatment of ED. This was in contrary to our study that might be explained by different selected age group (the mean age was older in the current study), different erectile function scoring index (the current study was IIEF-5 vs IIEF-EF) and different selected ED patients (non-responders in the present study vs ordinary ED cases). Bayraktar and Albayrak (2018) evaluated the efficacy of antiplatelet (aspirin 100 mg)therapy in vasculogenic erectile dysfunction (VED) for 6 weeks on large number of patients but these patients had a younger mean age than the current study. The patients were evaluated using IIEFEF and found that IIEF-EF score was significantly higher in the aspirin group than in the placebo group. In the current study, the number of patients is less and all patients were non-responders to on demand sildenafil and were evaluated using IIEF-5. Li et al. (2018) revealed the association between the use of aspirin or non-aspirin NSAIDs in ED and found that studies revealed that association between aspirin or non-aspirin NSAIDs and ED is controversial. The high frequency of drug use, further clinical and basic investigations should be conducted to clarify their exact relationship. Therefore, low-dose aspirin may be used in patients with ED for treatment purposes or for delaying penile atherosclerosis. However, there is a need for more extensive studies on this subject. Cui et al. (2015) investigated the efficacy and safety of tadalafil combined with sildenafil on demand compared with $5 \mathrm{mg}$ tadalafil 
once daily in the treatment of ED. The patients with ED were enrolled and randomly assigned to either treatment arm for a 12-week course, evaluated according to IIEF-5 score and showed that there is no significant difference among both groups but, analysis showed a statistically significant improvement only in the severe ED in the combination group compared with the monotherapy group. Therefore, the combination of long-acting and short-acting PDE5i may be an important direction for treating PDE5i non-responders.

\section{CONCLUSION}

The combination of sildenafil and tadalafil could represent a treatment option for sildenafil non-responder patients. Adding aspirin to sildenafil and tadalafil adds non-significant improvement in ED non-responders patients

Conflicts of interest: No conflicts of interest were encountered.

\section{REFERENCES}

1. Allen MS and Walter EE (2019): Erectile dysfunction: an umbrella review of metaanalyses of risk factors, treatment, and prevalence outcomes. The Journal of Sexual Medicine, 16(4):531-541.

2. Bayraktar Z and Albayrak S (2018): Antiplatelet (aspirin) therapy as a new option in the treatment of vasculogenic erectile dysfunction: a prospective randomized doubleblind placebo-controlled study. International urology and nephrology, 50(3):411-418.
3. Bayraktar $Z$ and Albayrak $S$ (2019): Efficacy and safety of combination of tadalafil and aspirin versus tadalafil or aspirin alone in patients with vascular erectile dysfunction: a comparative randomized prospective study. International urology and nephrology, 51(9):1491-1499.

4. Cui H, Liu B, Song Z, Fang J, Deng Y, Zhang S, Wang H, Wang Z (2015): Efficacy and safety of long-term tadalafil $5 \mathrm{mg}$ once daily combined with sildenafil $50 \mathrm{mg}$ as needed at the early stage of treatment for patients with erectile dysfunction. Andrologia, 47:20-24.

5. Fuster V and Sweeny J M (2011): Aspirin: a historical and contemporary therapeutic overview. Circulation, 123(7):768-778.

6. Lee $M$ and Sharifi $R$ (2018): Non-invasive management options for erectile dysfunction whena phosphodiesterase type 5 inhibitor fails. Drugs \& aging, 35(3):175-187.

7. Li T, Wu C, Fu F, Qin F, Wei Q, Yuan J (2018): Association betweeuse of aspirin or non-aspirin non-steroidal anti-inflammatory drugs and erectile dysfunction: A systematic review. Medicine, 97(28):25-29.

8. Retzler K (2019): Erectile Dysfunction: A Review of Comprehensive Treatment Options for Optimal Outcome. Journal of Restorative Medicine, 8(1):212-220.

9. Shamloul R, Ghanem $H$ and Abou-Zeid A (2004): Validity of the Arabic version of the sexual health inventory for men among Egyptians. Int J of Imp Res., 16:452-455.

10. Yafi F A, Jenkins L, Albersen M, Corona G, Isidori A M, Goldfarb S and Tan R (2016): Erectile dysfunction. Nature Reviews Disease Primers, 2(1):1-20. 
فاعلية عقار الأسبرين عند إضافته الي مثبطات الفوسفودايستريز على مرضي الضعف ألجنسي غير الإنير المستجبيين لمثبطات الفوسفوديزي عليستيريز

أحمد عبد المنعم على الأثقر، عبدالرعوف محمد المحسن، محمد إسماعيل محمد كامل قسم الأمراض الجلدية والتناسلية وأمراض الذكورة، كلية الطب، جامعة الأزهر

E-mail: ahmed.m2095@gmail.com

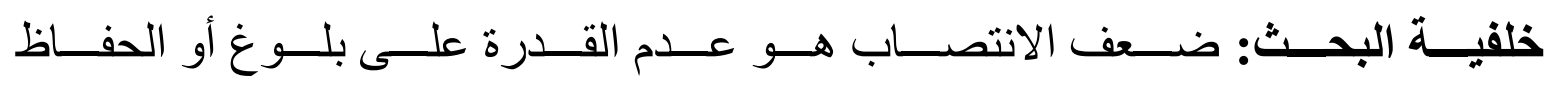

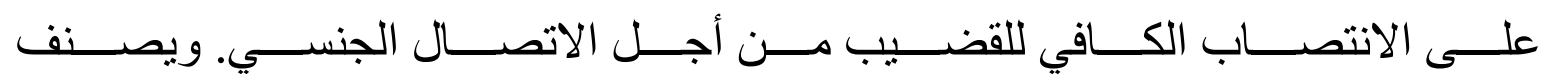

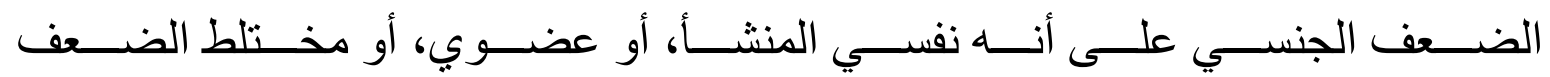

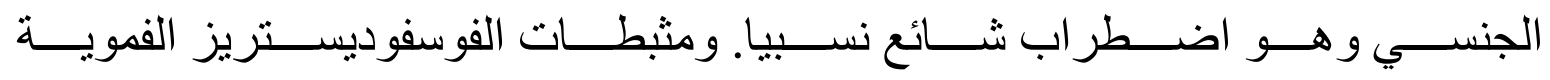

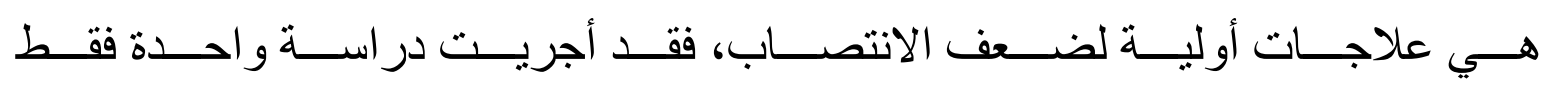

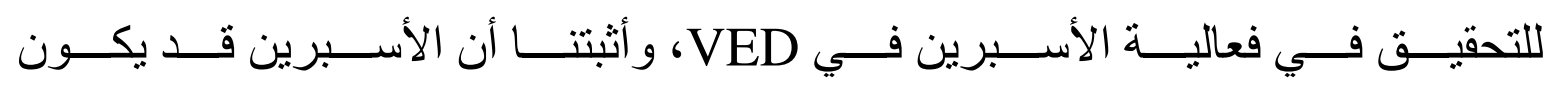

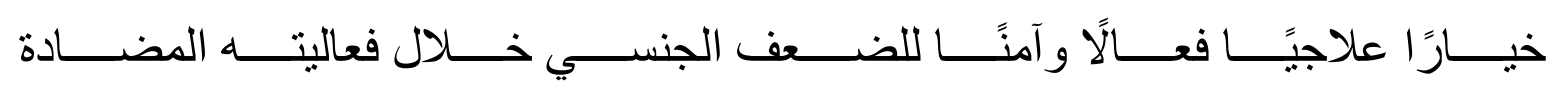

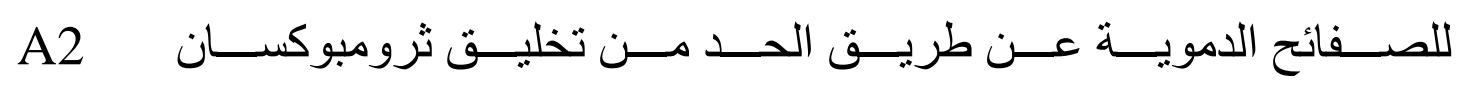
و هو عامل مُضاد قوي ومضيق للأو عية.

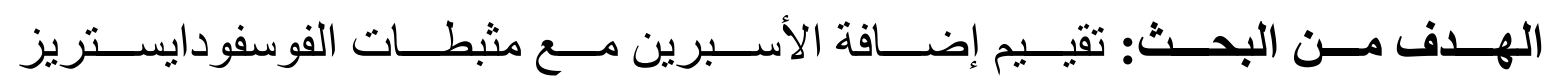

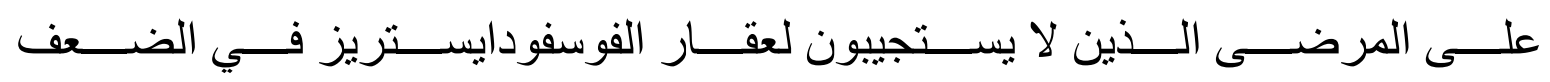

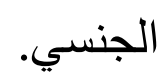

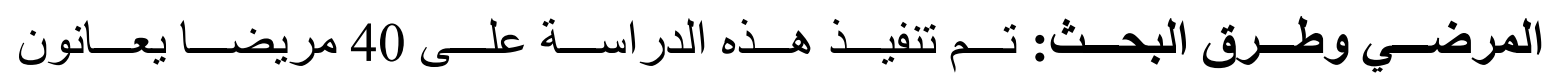

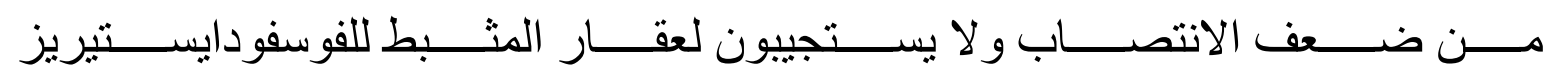

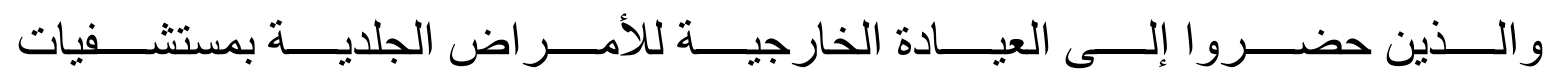

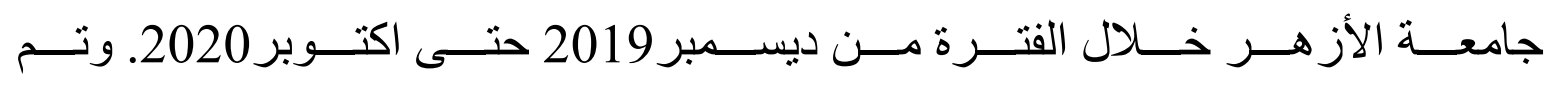

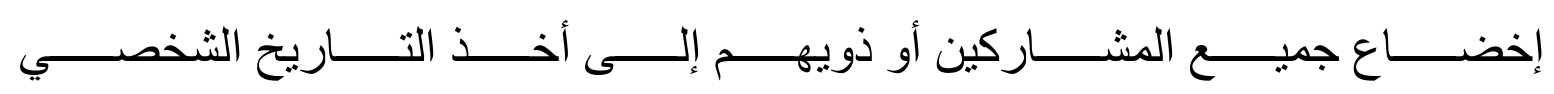

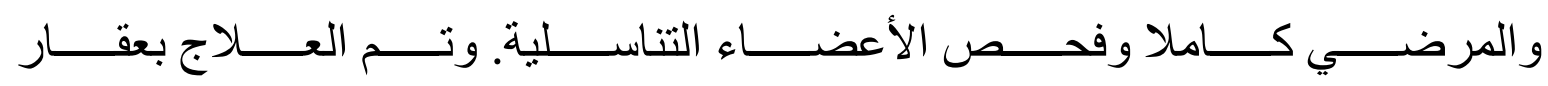




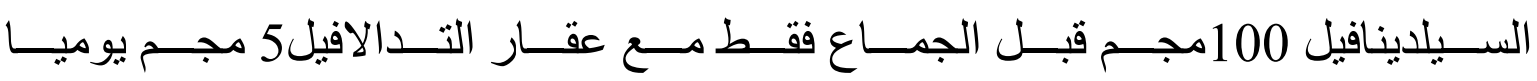

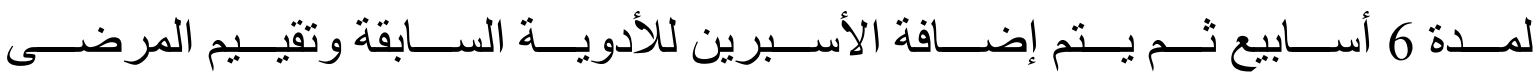

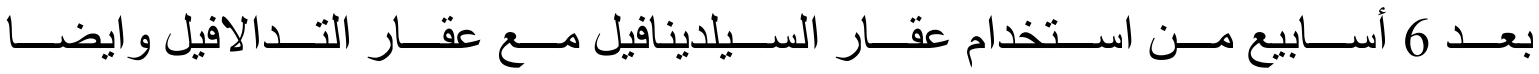

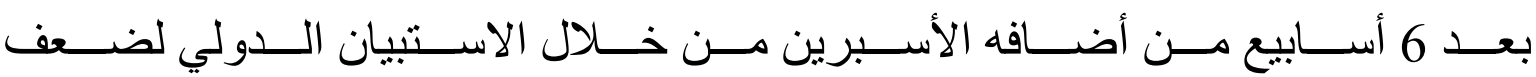
الانتصاب.

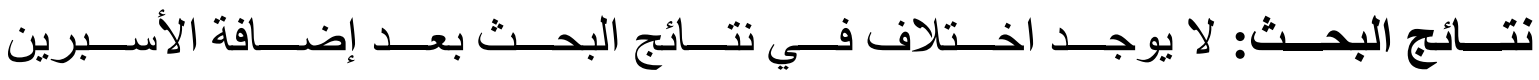
لعقار السيلدينافيل وعقار التدالافيل.

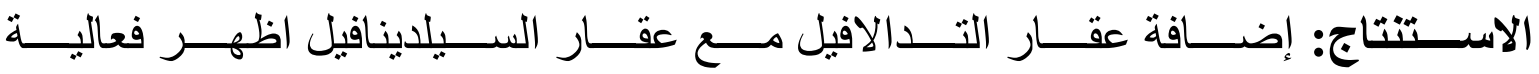

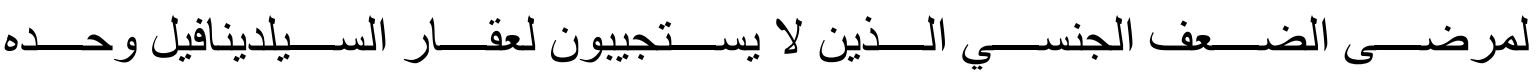

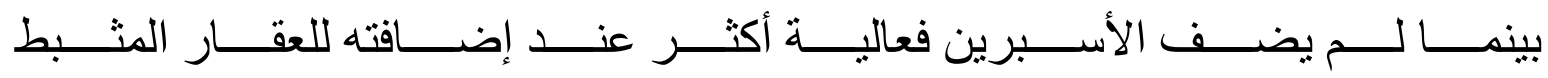

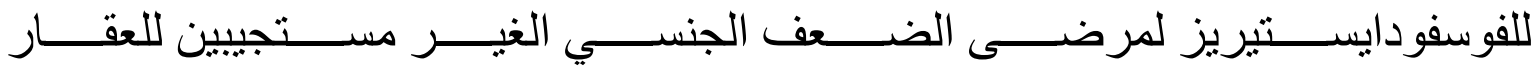
المثبط للفوسفودايستيريز في الضعف الجنسي. الكلمات الدالة: الضعف الجنسي, مثبطات الفوسفودايستريز, الأسبرين. 